\title{
The G972R variant of the insulin receptor substrate- 1 gene impairs insulin signaling and cell differentiation in 3T3L1 adipocytes; treatment with a PPAR $\gamma$ agonist restores normal cell signaling and differentiation
}

\author{
F Sentinelli ${ }^{1}$, E Filippi ${ }^{1}$, M G Cavallo ${ }^{1}$, S Romeo ${ }^{1}$, M Fanelli ${ }^{1}$ \\ and $\mathbf{M}$ G Baroni ${ }^{1,2}$ \\ ${ }^{1}$ Department of Clinical Sciences, Division of Endocrinology, Policlinico Umberto I, University of Rome 'La Sapienza', Viale del Policlinico 155 , 00161 Rome, \\ Italy \\ ${ }^{2}$ Department of Medical Sciences, University of Cagliari, Cagliari, Italy \\ (Requests for offprints should be addressed to M G Baroni; Email: marco.baroni@uniroma1.it)
}

\begin{abstract}
The insulin receptor substrate-1 (IRS-1) plays a central role in insulin sensitivity, and association studies have shown that the IRS-1 G972R variant is a risk factor for insulin resistance. However, how this mutation may lead to impaired insulin sensitivity is still to be determined. Our study aimed to evaluate, after transfection of the IRS-1 G972R variant in 3T3L1 adipocytes, the effect of this mutation on insulin signaling and on cell differentiation. The 3T3L1 cells were transfected with pcDNA3 expression vector containing either the human wild-type IRS-1 or the G972R variant. After induction of differentiation, the 3T3L1 transfected with wild-type IRS-1 differentiated in 6-8 days, while the cells transfected with G972R variant did not differentiate. To determine whether the defect in IRS-1 was responsible for this, we analyzed the expression of several genes involved in the insulin signaling pathway. Results showed that PPAR $\gamma$ expression was significantly reduced in cells transfected with the mutated IRS-1, together with a significant decrease in binding of
\end{abstract}

phosphatidylinositol-3 kinase (PI 3-kinase) to IRS-1 G972R and in PI 3-kinase activity. In addition, we observed that the interaction between the insulin receptor (IR) and the IRS-1 G972R protein was increased and that the autophosphorylation of the IR was significantly inhibited in 3T3L1-G972R cells compared with 3T3L1-WT. Treatment of the 3T3L1-G972R cells with pioglitazone (PIO), a PPAR $\gamma$ agonist, restored differentiation with higher level of PPAR $\gamma$ expression and restoration of PI 3-kinase binding to IRS-1 G972R and PI 3-kinase activity. IR autophosphorylation was also increased. Withdrawal of PIO in fully differentiated 3T3L1-G972R cells determined the reappearance of the insulin signaling defect. Finally, we observed higher levels of IRS-2 expression, suggesting that IRS-2 may play a more important role in adipocyte insulin signaling. In conclusion, IRS-1 G972R variant impairs insulin signaling, and treatment with $\operatorname{PPAR} \gamma$ agonist restores the normal phenotype of 3T3L1 cells.

Journal of Endocrinology (2006) 188, 271-285

\section{Introduction}

In the pathogenesis of common disorders, such as type 2 diabetes mellitus, hypertension and atherosclerosis, a central role is played by insulin resistance. In the search for susceptibility loci predisposing to insulin resistance, previous studies have identified a glycine to arginine substitution at codon 972 (G972R) in the insulin receptor substrate-1 (IRS-1) gene as being associated with impaired insulin action, particularly in obese patients (Clausen et al. 1995, Baroni et al. 2001). The IRS-1 gene, which plays a pivotal role in the signaling cascade activated by insulin, is therefore a strong candidate for the genetic susceptibility to insulin resistance.
After the binding of insulin to its receptor, the intrinsic tyrosine kinase activity of the receptor $\beta$-subunit is activated, thus catalyzing the phosphorylation of specific tyrosine residues on the IRS-1 protein. Phosphorylated IRS-1 binds to several cellular signal proteins, thus functioning as a multisite 'docking' protein linking the receptor kinase to the variety of cell functions regulated by insulin (Meyers \& White 1993). In particular, phosphorylated IRS-1 binds with high affinity to proteins with Src homology-2 domains, including phosphatidylinositol-3 kinase (PI 3kinase), a lipid kinase composed by a regulatory subunit (p85) and a 110-kDa catalytic subunit (p110) (Sakaue et al. 1998). Activated PI 3-kinase generates phospholipids that act by multiple mechanisms and that cooperate to regulate 
Akt activity. The PI 3-K/Akt cascade has been implicated in various insulin-dependent cellular processes, including cell survival, glucose transport and adipocyte differentiation (Magun et al. 1996, Franke et al. 1997, Ueki et al. 1998). A consequence of Akt binding to phospholipids is the translocation of Akt from the cytoplasm to the inner surface of the plasma membrane and its change of conformation, so that $\mathrm{Thr}^{308}$ and $\mathrm{Ser}^{473}$ residues become accessible for phosphorylation by the phosphoinositidedependent protein kinases PDK1 and PDK2. Activation of Akt also results from the phosphorylation at the two sites (Datta et al. 1999, Alessi 2001). However, the mechanisms by which the PI 3-K/Akt cascade is relayed to the nucleus to activate adipocyte differentiation are not well understood. In orchestrating adipocyte differentiation, the nuclear receptor peroxisome proliferator-activated receptor- $\gamma$ (PPAR $\gamma$ ), the CCAAT/enhancer-binding proteins (C/EBPs), and adipocyte determination and differentiation-dependent factor 1 (ADD-1) are key transcription factors (Kim \& Spiegelman 1996). PPAR $\gamma$ is induced early during the course of adipocyte differentiation, binds to specific DNA-response elements as a heterodimer with the RXR proteins, and plays a key role in adipocyte differentiation (Auwerx 1999). Another pathway activated by the tyrosine phosphorylation of IRSs by the insulin receptor (IR) is the mitogen-activated protein kinases (MAP kinases) pathway. MAP kinases belong to a group of protein-serine/threonine kinases that are activated in response to various stimuli (growth factors, neurotransmitters, differentiating agents and heat shock) and are involved in proliferation and differentiation processes, in particular by regulating the transcriptional activity of the nucleus (Porras et al. 1998).

To define the role of the G972R variant of IRS-1 gene in insulin signaling, we have transfected this variant in 3T3L1 adipocytes, and examined the proteins involved in IRS-1-mediated signaling, including those implicated in adipocyte differentiation. Our results demonstrate impairment in the differentiation process in 3T3L1-G972R, associated with several alterations of the insulin-signaling pathway, including a significant reduction of PPAR $\gamma$ expression. We also investigated the effects of a PPAR $\gamma$ agonist, pioglitazone (PIO), on the molecular alterations in IRS-1-mediated signaling associated with the G972R variant. PPAR $\gamma$ agonists, also known as thiazolidinediones (TZDs), are a class of antidiabetic agents that act by improving insulin sensitivity (Nolan et al. 1994, Zierath et al. 1998). TZDs exert their antidiabetic actions by various mechanisms: enhancing insulin signaling, increasing glucose transporters and uptake, lowering plasma FFA, reducing hepatic glucose production, decreasing tumor necrosis factor- $\alpha$ levels in muscle and increasing plasma adiponectin levels (Maeda et al. 2002). PPAR $\gamma$ agonists are direct ligands for PPAR $\gamma$ (Spiegelman 1998), and promote fat cell differentiation by the activation of several adipocyte-specific genes.

\section{Materials and Methods}

\section{Cell culture condition and treatment}

Murine 3T3L1 preadipocytes were maintained in DMEM/high-glucose medium supplemented with piruvic acid $(110 \mathrm{mg} / \mathrm{l})$, sodium hydrogen carbonate $\left(1.5 \mathrm{~g} / \mathrm{l}\right.$ at $\left.5 \% \mathrm{CO}_{2}\right)$ and $10 \%$ calf serum. Differentiation of stable transfected 3T3L1 was induced by exposing confluent cells to insulin $(1 \mu \mathrm{M})$, isobutylmethylxanthine $(0 \cdot 5 \mathrm{mM})$, and dexamethasone $(0 \cdot 25 \mu \mathrm{M})$ (all from Sigma) for 2 days, and then to insulin $(1 \mu \mathrm{M})$ alone for another 2 days. The medium was changed every 2 days until day 8 . The TZD compound PIO (kindly supplied by Takeda Chemical Industries, Osaka, Japan) was added at $1 \mu \mathrm{M}$ from the induction step of differentiation, and cells were cultured with PIO until full differentiation. For long-term PIO treatment, fully differentiated adipocytes at day 8 of differentiation were incubated for an extra $48 \mathrm{~h}$ in the presence or absence of $10 \mu \mathrm{M}$ PIO followed by stimulation with $100 \mathrm{nM}$ insulin. For time-course study, 3T3L1 cells were placed in DMEM supplemented with $2 \%$ calf serum for $(16-20 \mathrm{~h})$ and then stimulated for the indicated times $(0-40 \mathrm{~min})$ at $37^{\circ} \mathrm{C}$ in the presence of $100 \mathrm{nM}$ insulin.

\section{Oil Red O staining}

Cells were washed three times with PBS, fixed by $10 \%$ formalin in PBS for $1 \mathrm{~h}$ at room temperature, washed once again with PBS, and then stained with $60 \%$ filtered Oil Red O stock solution (0.5 g Oil Red O (Sigma) in $100 \mathrm{ml}$ isopropanol) for $20 \mathrm{~min}$, washed four times with water and analyzed under a microscope.

\section{Construction and expression of human IRS-1 cDNAs in $3 T 3 L 1$ cells}

pcDNA3 expression vectors (Invitrogen) containing human wild-type (WT) IRS-1 or the G972R variant were constructed as previously described (Imai et al. 1997). 3T3L1 cells were stably transfected with $1 \mu \mathrm{g}$ pcDNA3 alone, WT pcDNA3 IRS-1 or pcDNA3 G972R IRS-1, and suspended with $20 \mu \mathrm{l}$ lipofectamine in $1 \mathrm{ml}$ serumfree DMEM (Invitrogen). The cells were incubated with a selective medium containing $0.4 \mathrm{mg} / \mathrm{ml}$ geneticin G-418 sulfate (Invitrogen). From all the G-418-resistant stable cell clones obtained from the transfection (seven clones with the WT IRS-1 and five clones with the G972R variant), we selected clones expressing similar amounts of IRS-1 protein by analyzing lysates by Western blotting. We selected also clones with the G972R variant expressing high and low amounts of IRS-1 protein. We performed all the experiments reported in the paper with three clones expressing WT IRS-1 and with two clones 
expressing the G972R variant. Additionally, we performed experiments in two clones expressing the empty vector.

IR and IRS-1 tyrosine phosphorylation and association with the $p 85$ subunit of PI 3-kinase

The transfected 3T3L1 were placed in DMEM containing $2 \%$ calf serum $(16-20 \mathrm{~h}$ ) and then incubated for $5 \mathrm{~min}$ at $37^{\circ} \mathrm{C}$ in the presence or absence of $100 \mathrm{nM}$ insulin. The cells were then lysed for $45 \mathrm{~min}$ at $4{ }^{\circ} \mathrm{C}$ with lysis buffer $(137 \mathrm{mM} \mathrm{NaCl}, 20 \mathrm{mM}$ Tris- $\mathrm{HCl}$ (pH 7.6), $1 \mathrm{mM}$ $\mathrm{MgCl}_{2}, 1 \mathrm{mM} \mathrm{CaCl}, 2 \mathrm{mM}$ EDTA, 10\% glycerol, $10 \mathrm{mM} \quad \mathrm{Na}_{4} \mathrm{P}_{2} \mathrm{O}_{4}, 100 \mu \mathrm{M}$ sodium orthovanadate, $10 \mathrm{mM} \mathrm{NaF}, 10 \mu \mathrm{g} / \mathrm{ml}$ leupeptin, $2 \mathrm{mM}$ phenylmethylsulfonylfluoride and 1.5\% Nonidet P-40). Insoluble materials were removed by centrifugation, and the supernatants were incubated with polyclonal anti-IRS-1 or anti-IR antibody (Upstate Biotechnology, Lake Placid, NY, USA), followed by incubation with protein A-Sepharose for $2 \mathrm{~h}$ at $4{ }^{\circ} \mathrm{C}$. The immunoprecipitated proteins were resuspended in Laemmli buffer, resolved by SDS-PAGE and transferred onto nitrocellulose membrane (Hybond ECL, Amersham). The membranes were incubated with polyclonal antiphosphotyrosine antibody (Transduction Laboratories, Lexington, KY, USA) or with anti-PI 3-kinase p85 (Upstate Biotechnology), followed by incubation with HRP-conjugated secondary antibodies. Immunoreactive bands were detected with the ECL kit (Amersham) and Biomax Light Kodak. Quantification was determined by densitometric scanning. All blots were normalized for the amount of immunoprecipitated proteins.

\section{IRS-1-associated PI 3-kinase activity}

Transfected 3T3L1 were placed in DMEM containing 2\% calf serum $(16-20 \mathrm{~h})$ and then incubated for $5 \mathrm{~min}$ at $37^{\circ} \mathrm{C}$ in the presence or absence of $100 \mathrm{nM}$ insulin. The cells were then lysed for $20 \mathrm{~min}$ with $1 \mathrm{ml}$ ice-cold lysis buffer (137 mM NaCl, $20 \mathrm{mM}$ Tris- $\mathrm{HCl}$ (pH 7.4), $1 \mathrm{mM}$ $\mathrm{MgCl}_{2}, 1 \mathrm{mM} \mathrm{CaCl}, 0 \cdot 1 \mathrm{mM}$ sodium orthovanadate, $1 \%$ Nonidet P-40 and $1 \mathrm{mM}$ phenylmethylsulfonylfluoride). An amount of $50 \mu \mathrm{g}$ whole-cell lysate was incubated with anti-IRS-1 antibody, followed by incubation with protein A-Sepharose for $2 \mathrm{~h}$ at $4{ }^{\circ} \mathrm{C}$, and washed with TNE buffer (10 mM Tris- $\mathrm{HCl}$ (pH 7.4), $150 \mathrm{mM} \mathrm{NaCl}, 5 \mathrm{mM}$ EDTA and $0.1 \mathrm{mM}$ sodium orthovanadate). The PI 3-kinase activity was studied in immunoprecipitates with a PI 3-kinase ELISA kit (Echelon Biosciences, Salt Lake City, UT, USA).

\section{Immunoblotting}

Antibodies against the serine 473/474, threonine 308/309 phosphorylated regions, and the nonphosphorylated regions of Akt1 and Akt2, antiphospho-PDK1 $\left(\mathrm{Ser}^{241}\right)$ polyclonal antibody, and antiphospho-p42/p44 MAP kinases monoclonal antibody were all from Cell Signaling Technology (Beverly, MA, USA). Polyclonal anti-IRS-2, anti-phospho-FKHRL1 $\left(\mathrm{Thr}^{32}\right)$, and monoclonal anti$\operatorname{PPAR} \gamma$ antibodies that react with both PPAR $\gamma 1$ and PPAR $\gamma 2$ forms, were from Santa Cruz Biotechnology (Santa Cruz, CA, USA).

An amount of 30-40 $\mu$ g total cell lysates, determined by the Bradford assay, were separated by SDS-PAGE and transferred to nitrocellulose membranes. Membranes were incubated with the specific primary antibody followed by incubation with HRP-conjugated secondary antibodies. Proteins were detected by enhanced chemiluminescence, and densities of blots were quantified by densitometric scanning. Percent differences in protein binding and expression were calculated by computing the percent reduction/increase relative to that in WT cells (binding/ expression in WT: 100= binding/expression in G972R:x). Where necessary, immunoblots were stripped of antibodies, according to the manufacturer's instructions, and reprobed with different antibody. To ensure removal of antibodies, membranes were then incubated with ECL (Amersham) detection reagents and exposed to film.

\section{Statistical analysis}

Differences in the expression of mRNA and protein levels between the cell lines were analyzed by unpaired or paired Student's $t$-test where appropriate. A $P$ value of less than $0 \cdot 05$ was considered statistically significant.

\section{Results}

Adipocyte differentiation in 3T3L1-G972R cells is impaired

3T3L1 cells were stably transfected with pcDNA3 expression vectors containing human WT IRS-1 or the G972R variant. In all transfected cell clones used in this study, expression of WT IRS-1 and of G972R variant was about 1.9-fold-higher than that of the endogenous IRS-1, as detected by immunoblotting. Thus, similar amounts of recombinant IRS-1 were observed in 3T3L1-WT and 3T3L1-G972R cells (data not shown).

Differentiation in transfected 3T3L1 was induced as described in Materials and Methods. After induction, preadipocytes carrying WT IRS-1 rapidly accumulated fat, and a fully differentiated phenotype with $80-90 \%$ of the cells containing multilocular fat droplets could be observed 6 days after induction (Fig. 1A). In contrast, only $20-30 \%$ of the 3 T3L1 cells carrying the G972R variant were able to accumulate fat (Fig. 1B). Moreover, 3T3L1 cells transfected with pcDNA3 alone (empty vector) differentiated normally in 6-8 days, confirming that no significant cytotoxicity was caused by the control transfection (data not shown). 


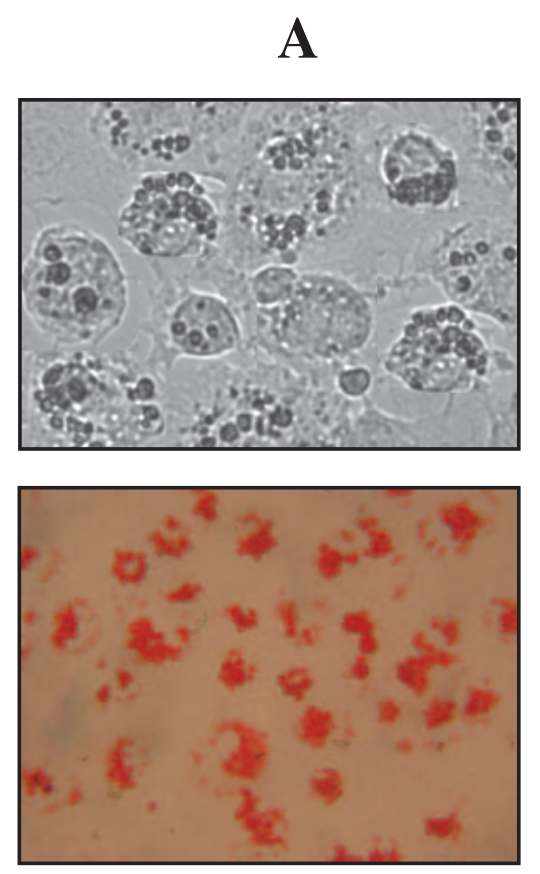

3T3L1-WT

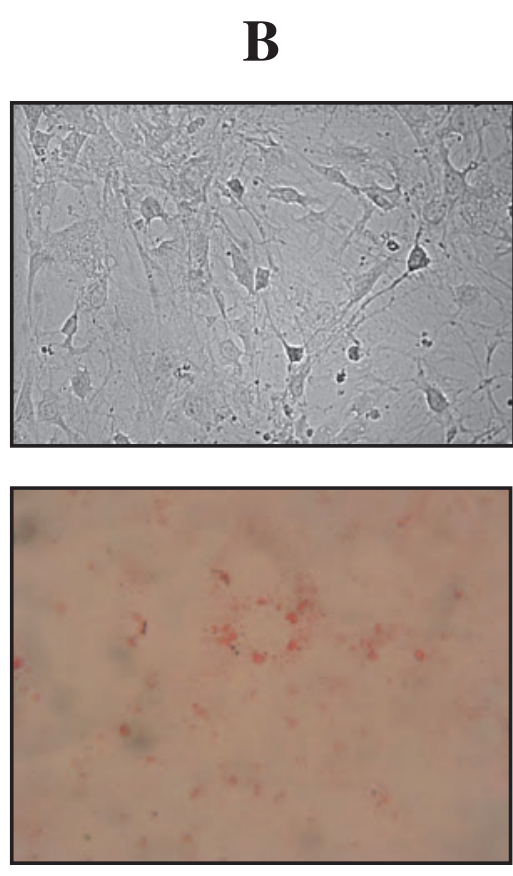

3T3L1-G972R
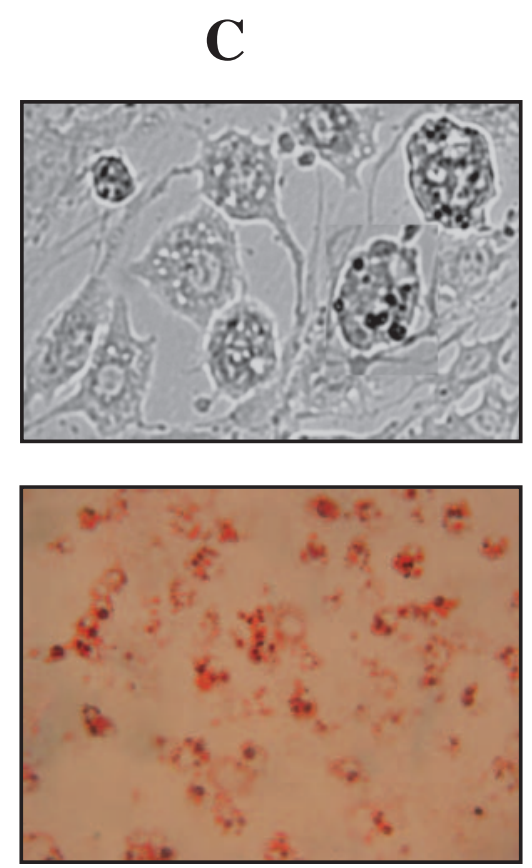

3T3L1-G972R-PIO

Figure 1 Effect of the G972R variant of IRS-1 gene on differentiation of 3T3L1 cells into adipocytes (upper and lower panel). 3T3L1 transfected with wild-type (A) and G972R variant (B) were induced to differentiate by exposing confluent cells to insulin, isobutylmethylxanthine and dexamethasone, as described in Materials and Methods. (C) Pioglitazone (PIO) was added at $1 \mu \mathrm{M}$ from the induction step of differentiation, and 3T3L1-G972R cells were cultured in the presence of PIO until full differentiation. The degree of adipogenic differentiation was evaluated by Oil Red-O staining at day 8 of differentiation (20) (lower panel).

To determine whether the G972R variant of the IRS-1 gene could cause the defective differentiation process in 3T3L1 cells, we assessed the expression of PPAR $\gamma$ during adipocyte differentiation by immunoblotting and RT-PCR. In 3T3L1-WT cells, both forms of PPAR $\gamma, \gamma 1$ and $\gamma 2$, are low at day 0 and increase as expected during the differentiation process (Fig. 2A). Conversely, in 3T3L1-G972R cells, the expression of PPAR $\gamma$ gene was greatly reduced (Fig. 2B). Compared with 3T3L1-WT cells, PPAR $\gamma$ expression in 3T3L1-G972R cells was 4.1fold lower at day 2 of differentiation $(P<0 \cdot 03), 3 \cdot 8$-fold lower at day $4 \quad(P<0 \cdot 016), 3 \cdot 1$-fold lower at day 6 $(P<0 \cdot 011)$ and $3 \cdot 5$-fold lower at day $8(P<0 \cdot 01)$.

Furthermore, the expression by RT-PCR of specific adipocytic differentiation markers, such as adiponectin (adipoQ) and adipsin, was reduced in the 3T3L1-G972R cells compared with the 3T3L1-WT cells (data not shown).

\section{IRS-1 tyrosine phosphorylation and binding of p85 subunit} of PI 3-kinase

To clarify the possible mechanisms by which the G972R variant could affect insulin signaling, we studied tyrosine phosphorylation of IRS-1 and its binding to the p85 subunit of PI 3-kinase. Equal amounts of total protein from transfected 3T3L1 cells, either stimulated or not with insulin, were immunoprecipitated with anti-IRS-1 antibody, subjected to SDS-PAGE, and immunoblotted with antiphosphotyrosine or anti-PI 3-kinase p85 antibodies (Fig. 3A and B). Basal phosphorylation of IRS-1 in unstimulated cells showed no significant difference between 3T3L1-WT and 3T3L1-G972R cells. Quantitation of the protein bands, after correction for the amount of IRS-1 protein level immunoprecipitated, showed that, after insulin stimulation, IRS-1 phosphorylation was increased by 1.5 -fold $(P<0.02)$ in 3 T3L1-WT and $1.5-$ fold $(P<0.02)$ in 3T3L1-G972R, compared with the basal in each cell line. In 3T3L1-G972R cells, insulinstimulated phosphorylation of IRS-1 was $17 \%$ lower than with 3T3L1-WT $(P<0 \cdot 03)$ (Fig. 3A).

Basal binding of $\mathrm{p} 85$ subunit to IRS- 1 in unstimulated cells showed no significant differences between 3T3L1G972R and 3T3L1-WT cells. Quantitation of the protein bands, after correction for the amount of immunoprecipitated IRS-1, confirmed that, after insulin stimulation, binding of $\mathrm{p} 85$ protein to IRS- 1 was increased by $1 \cdot 5$-fold $(P<0.03)$ in 3 T3L1-WT and by 1.3 -fold $(P<0.05)$ in 3T3L1-G972R; thus, in 3T3L1-G972R, binding of p85 


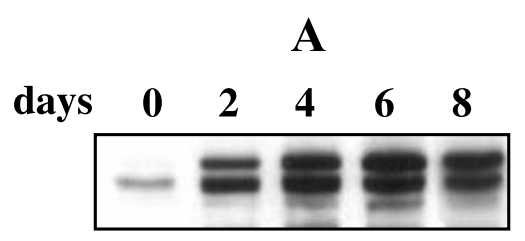

3T3L1-WT
B

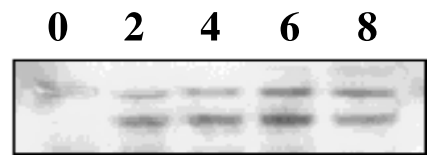

3T3L1-G972R

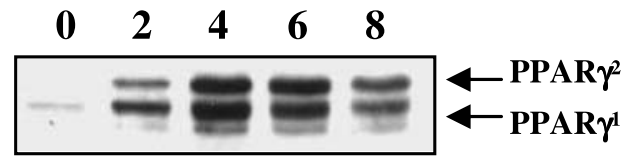

3T3L1-G972R + PIO

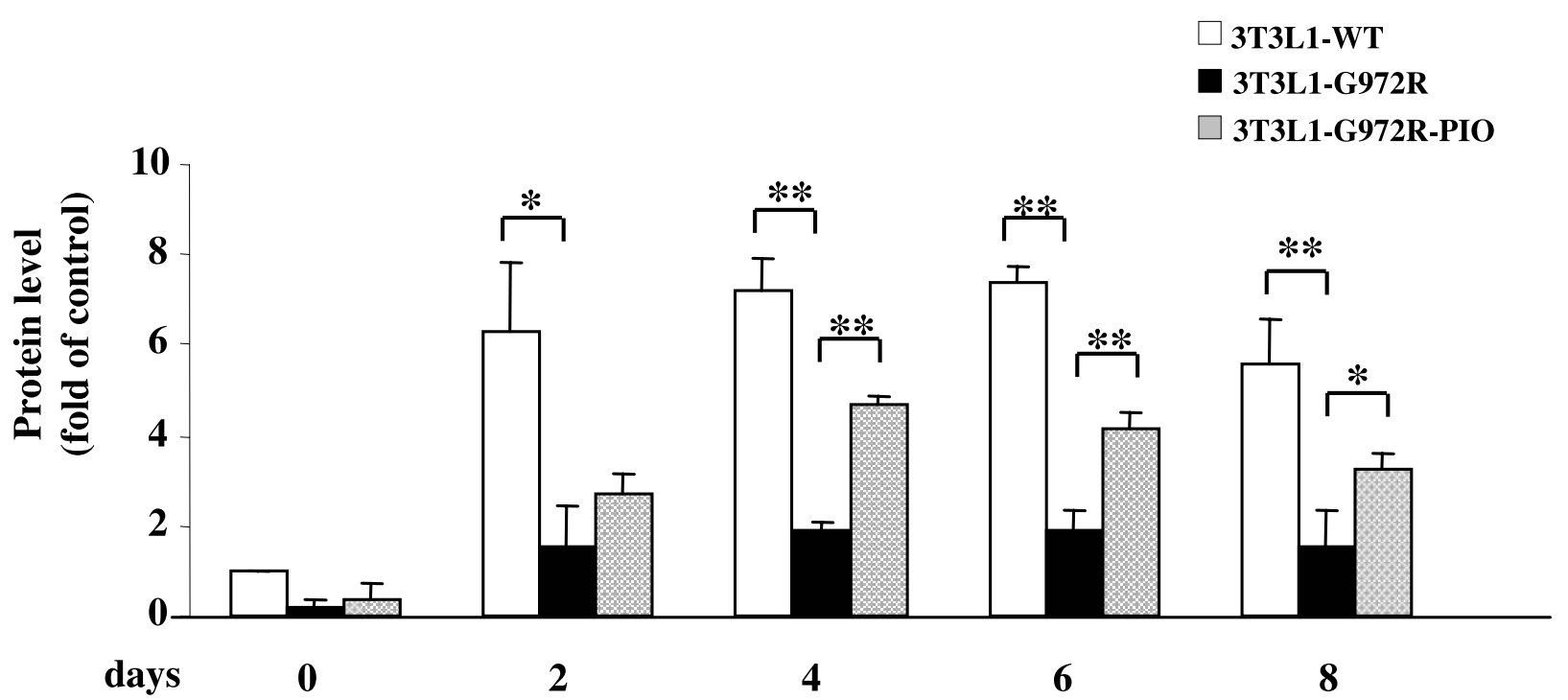

Figure 2 PPAR $\gamma$ expression during adipocyte differentiation. 3T3L1 with wild-type (A) and G972R variant (B) of the IRS-1 gene were differentiated, as described in Materials and Methods. Cell lysates were immunoblotted with anti-PPAR $\gamma$ antibody. (C) PIO was added at $1 \mu \mathrm{M}$ from the induction step of differentiation, and 3T3L1-G972R cells were cultured in the presence of PIO until full differentiation. The protein levels of PPAR $\gamma$ were normalized by the value in control cells at day 0 of differentiation. Data represent three independent experiments. Only significant comparison between 3T3L1-G972R and 3T3L1-WT cells and between 3T3L1-G972R and 3T3L1-G972R-PIO cells are shown. ${ }^{\star} P<0 \cdot 05 ;{ }^{*} P<0 \cdot 02$.

to IRS-1 was $25 \%$ lower $(P<0 \cdot 02)$ in response to insulin than in cells expressing the WT protein (Fig. 3B). The decrease was not due to a decrease in IRS-1 protein, as Western blots of lysates from 3T3L1 cells, either stimulated or not with insulin, revealed equal amounts of IRS-1 protein between the 3T3L1-WT and 3T3L1-G972R cells (Fig. 3, top panel).

\section{PI 3-kinase activity in 3T3L1 cells expressing WT IRS1 or G972R variant}

To determine whether the reduced interaction between IRS-1 and p85 protein in cells expressing the G972R variant resulted in reduced PI 3-kinase activity, equal amounts of total protein of transfected 3T3L1, stimulated or not with insulin, were immunoprecipitated with antiIRS-1 antibody and subjected to kinase reactions, as described in Materials and Methods. Quantitation of the colorimetric signal of the ELISA plate revealed that 3T3L1-WT and 3T3L1-G972R cells had similarly low levels of basal PI 3-kinase activity. After insulin stimulation, the IRS-1-associated PI 3-kinase activity was increased by 8.3 -fold $(P<0.002)$ in 3T3L1-WT and 4.6 -fold $(P<0.03)$ in 3T3L1-G972R cells. Therefore, in 3T3L1-G972R cells, PI 3-kinase activity was 35\% lower $(P<0 \cdot 004)$ in response to insulin than in 3T3L1-WT cells (Fig. 4).

Insulin receptor (IR) tyrosine phosphorylation and interaction with IRS-1

A very recent study showed that the presence of the G972R polymorphism markedly enhances the association of the IRS-1 gene with the IR, allowing IRS-1 to act as an inhibitor of IR autophosphorylation (McGettrick et al. 2004).

To further investigate how the presence of the G972R polymorphism altered IRS-1 function, we studied the interaction between IRS-1 and the IR. Equal amounts of 
IP: IRS-1 Ab

IB: IRS-1 Ab

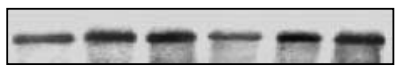

IB: pY Ab

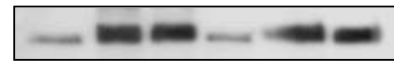

IB: $\mathbf{p 8 5}$ Ab

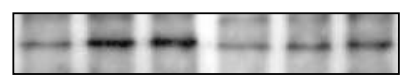

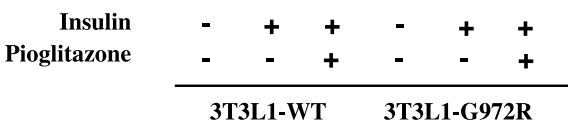

$\mathbf{A}$
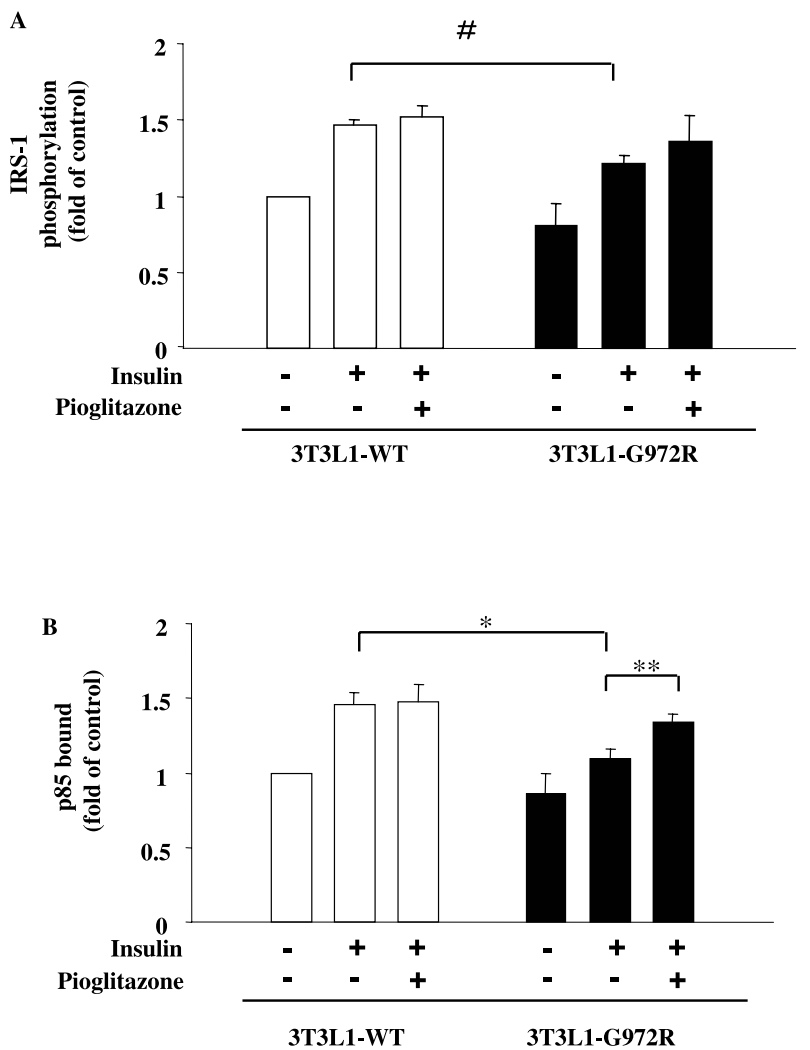

IP: IRS-1 Ab

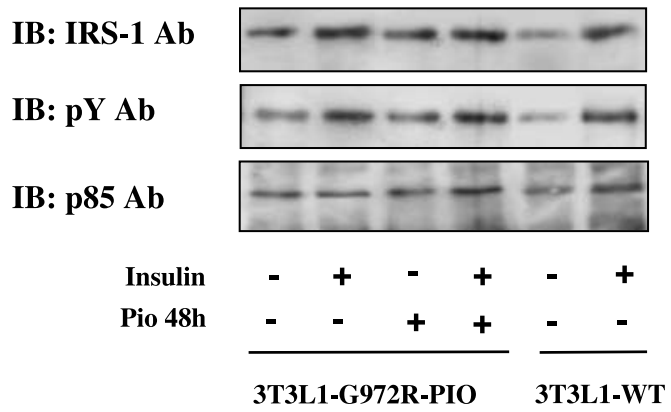

C

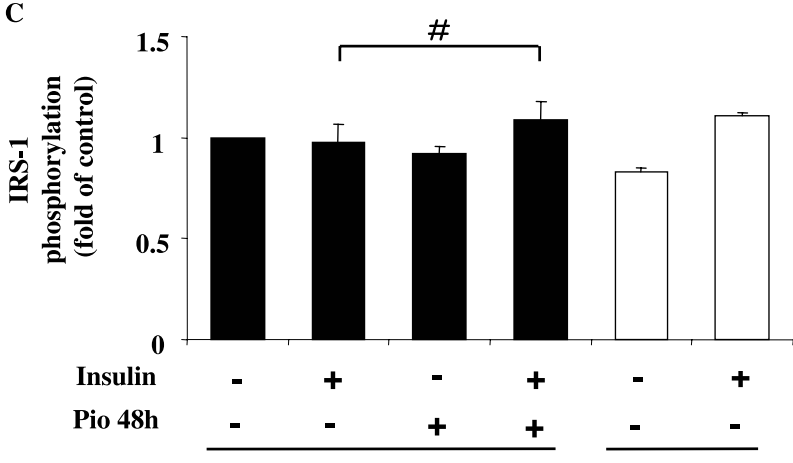

3T3L1-G972R-PIO

3T3L1-WT

D

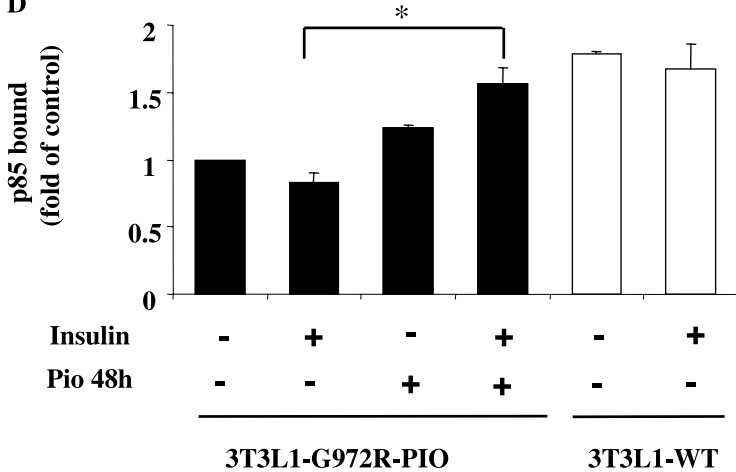

Figure 3 Tyrosine phosphorylation (A) and association of the p85 subunit of PI 3-kinase (B) of wild-type and G972R IRS-1 in 3T3L1 cell line. Top panel shows relative western blots. 3T3L1-WT or 3T3L1-G972R cells were incubated for 5 min in the presence or absence of $100 \mathrm{nM}$ insulin, or for $48 \mathrm{~h}$ with $10 \mu \mathrm{M}$ PIO followed by stimulation with insulin. Cell lysates were immunoprecipitated with anti-IRS1 antibody, and immunoblotted with antiphosphotyrosine antibody and with anti-PI 3-kinase p85. Results represent three independent experiments. Fold difference is by comparison with values in control cells. The relative levels of tyrosine phosphorylation and binding of the p85 subunit were quantified by densitometric scanning, and the values were divided by the values of IRS- 1 protein immunoprecipitated. (A) \#Significant decrease in 3T3 L1-G972R compared with 3T3L1-WT cells after insulin $(P<0 \cdot 05)$; (B) * significant decrease in 3T3L1-G972R compared with 3T3L1-WT cells after insulin $(P<0 \cdot 05)$; ${ }^{* *}$ significant increase in 3 T3L1-G972R cells after PIO treatment $(P<0 \cdot 05)$. Tyrosine phosphorylation $(C)$ and association of the p85 subunit of PI 3-kinase (D) in fully differentiated

3T3L1-G972R-PIO and in wild-type cells. Cells were incubated for an extra $48 \mathrm{~h}$ after day 8 of differentiation in the presence or absence of $10 \mu \mathrm{M}$ PIO followed by stimulation with insulin. (C) \#Significant decrease in 3T3L1-G972R-PIO with no 48-h PIO treatment compared with 3T3L1-G972R-PIO cells after 48-h PIO $(P<0 \cdot 05)$; (D) *significant decrease in 3T3L1-G972R-PIO without 48-h PIO treatment compared with 3T3L1-G972R-PIO cells after 48-h PIO $(P<0 \cdot 005)$. 


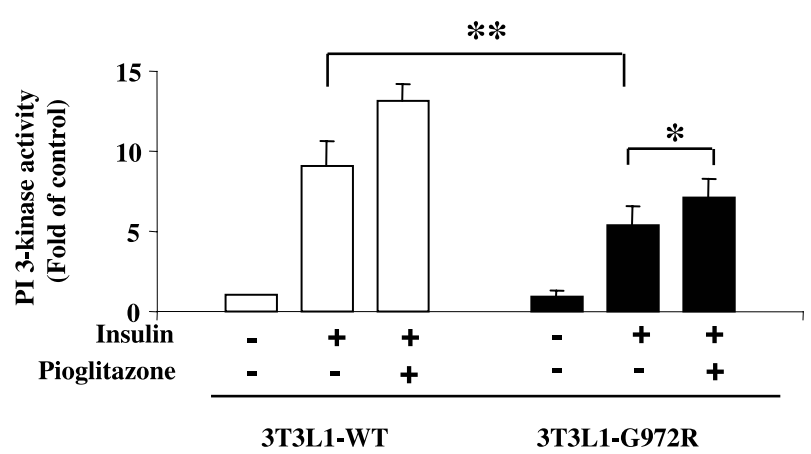

Figure 4 IRS-1 associated PI 3-kinase activity in 3T3L1 cells transfected with wild-type IRS-1 and G972R variant. Cells were incubated for $5 \mathrm{~min}$ in the presence or absence of $100 \mathrm{nM}$ insulin or for $48 \mathrm{~h}$ with $10 \mu \mathrm{M}$ PIO followed by stimulation with insulin. PI 3-kinase activity was quantified in immunoprecipitates with the ELISA plate reader. Data represent three independent experiments. Results are normalized for the values in control cells; ${ }^{* *}$ significant decrease in 3T3L1-G972R compared with 3T3L1-WT cells after insulin $(P<0 \cdot 01)$; ${ }^{*}$ significant increase in 3T3L1-G972R cells after $\mathrm{PIO}$ treatment $(P<0 \cdot 05)$.

total protein from transfected 3T3L1 cells, either stimulated or not with insulin, were immunoprecipitated with antibody against the IR, subjected to SDS-PAGE, and immunoblotted with antiphosphotyrosine or anti-IRS-1 antibodies (Fig. 5). Quantitation of the protein bands, after correction for the amount of IR protein level immunoprecipitated, showed that basal binding of IRS-1 to the IR in unstimulated cells was $1 \cdot 24$-fold $(24 \%)$ $(P<0 \cdot 03)$ higher in 3T3L1-G972R than in 3T3L1-WT cells. After insulin stimulation, binding of IRS-1 protein to the IR was increased by $1 \cdot 1$-fold $(P=\mathrm{NS})$ in 3T3L1-WT and by $1 \cdot 1$-fold $(P=\mathrm{NS})$ in 3T3L1-G972R cells; thus, in 3T3L1-G972R cells, binding of IRS-1 to the IR was $1 \cdot 2$-fold $(24.5 \%)(P<0.02)$ higher in response to insulin than in cells expressing the WT protein (Fig. 5A).

Immunoblotting the same samples with antiphosphotyrosine antibody showed that insulin-stimulated tyrosine phosphorylation of the IR in 3T3L1-G972R was 52\% of that in 3T3L1-WT $(P<0.003)$ (Fig. 5B).

\section{Serine and threonine Akt phosphorylation during} differentiation of transfected 3T3L1

The activation of PI 3-kinase by insulin is an upstream step in stimulation of several serine/threonine kinases, including the proto-oncogene product Akt (also known as protein kinase B). Activation of Akt is considered an important step in adipocyte differentiation. We assessed the activation of Akt during adipocyte differentiation by immunoblotting with antibodies specific for both $\mathrm{Th}^{308}$ and $\mathrm{Ser}^{473}$ phosphorylated forms of Akt. In 3T3L1-WT cells, high levels of serine and threonine Akt phosphorylation are present at day 0 of differentiation, but
IP: IR- $\boldsymbol{\beta}$ Ab
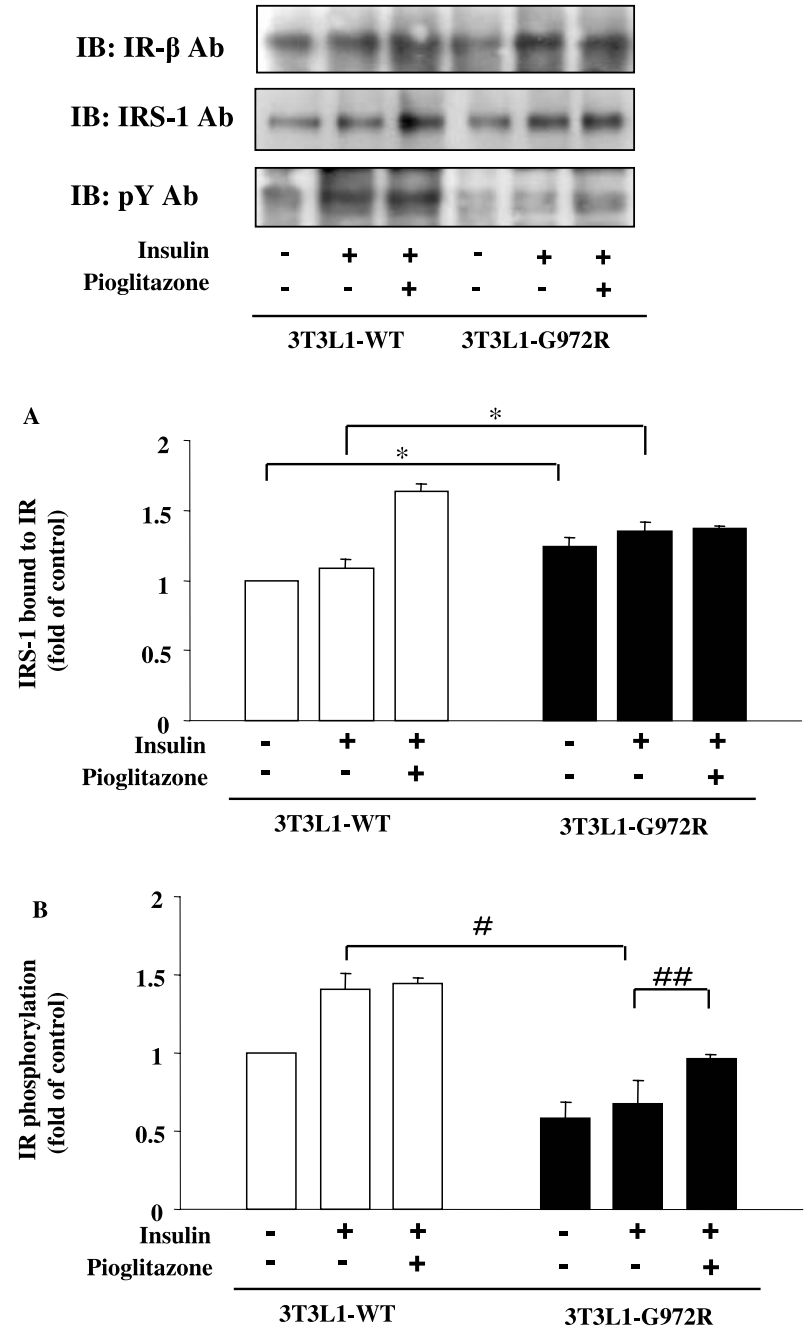

Figure 5 IR association with IRS-1 (A) and its tyrosine phosphorylation (B) in transfected 3T3L1 cell line. Top panel shows relative western blots. 3T3L1-WT or 3T3L1-G972R cells were incubated for $5 \mathrm{~min}$ in the presence or absence of $100 \mathrm{nM}$ insulin, or for $48 \mathrm{~h}$ with $10 \mu \mathrm{M}$ of PIO followed by stimulation with insulin. Cell lysates from 3T3L1-WT or 3T3L1-G972R cells were immunoprecipitated with anti-IR antibody, and immunoblotted with antiphosphotyrosine antibody and with anti-IRS-1. Results represent three independent experiments. Fold difference was calculated by comparison with values in control cells. The relative levels of tyrosine phosphorylation and binding of the IRS-1 protein were quantified by densitometric scanning, and the values were divided by the values of IR protein immunoprecipitated. (A) *Significant increase of IR-IRS-1 binding in 3T3L1-G972R compared with 3T3L1-WT cells before and after insulin $(P \leq 0 \cdot 03)$. (B) \#Significant decrease in 3T3L1-G972R compared with 3T3L1-WT cells after insulin $(P<0.003)$; \#\#significant increase in 3T3L1-G972R cells after PIO treatment $(P<0 \cdot 05)$.

phosphorylation decreases during differentiation (Fig. 6A and B). However, in 3T3L1-G972R cells, the levels of Akt phosphorylation remained high during all times of 


\section{WB: pSer-Akt Ab}
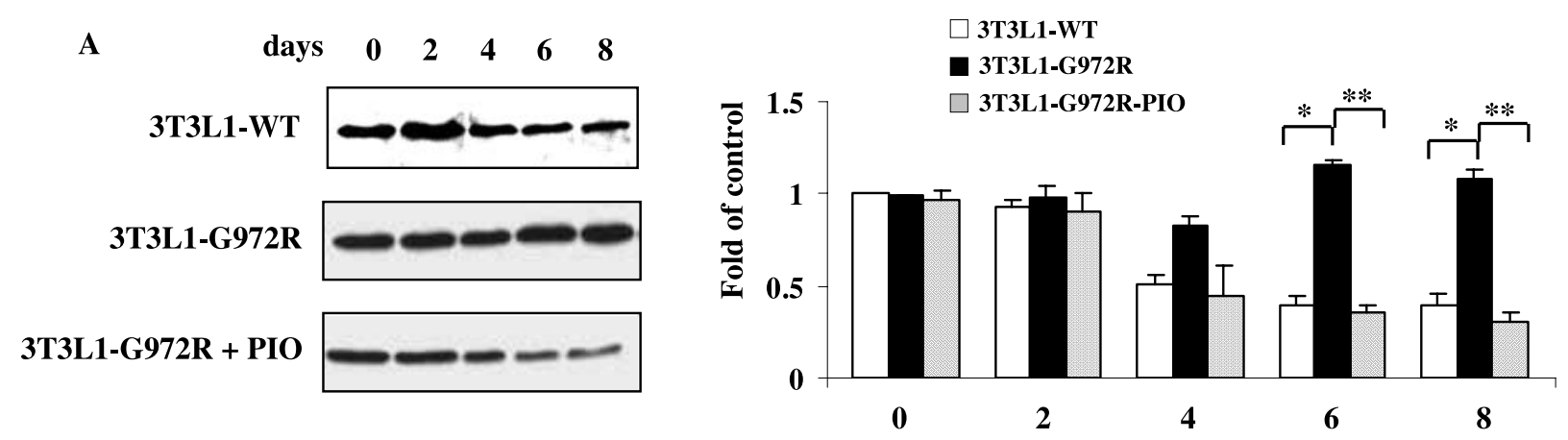

B

$\begin{array}{llllll}\text { days } & 0 & 2 & 4 & 6 & 8\end{array}$
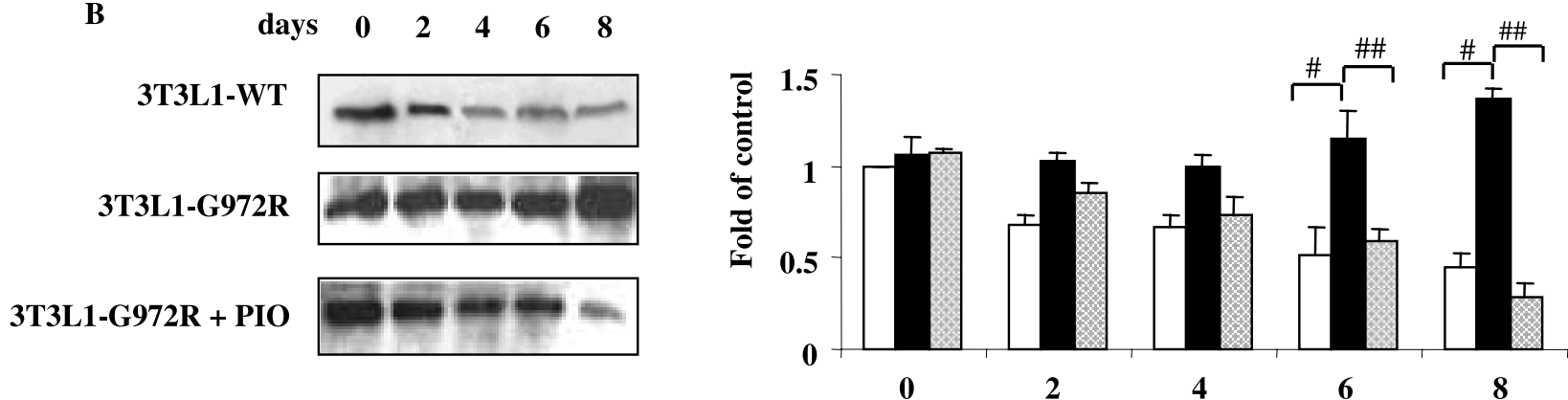

Figure 6 Akt serine $(A)$ and threonine (B) phosphorylation during adipocyte differentiation. Cell lysates were immunoblotted with antiphospho-Akt $\left(\mathrm{Ser}^{473}\right)$ or antiphospho-Akt $\left(\mathrm{Thr}^{308}\right)$ antibody. PIO was added at $1 \mu \mathrm{M}$ from the induction step of differentiation until full differentiation. Protein levels of phosphorylated Akt were normalized by the value in control cells at day 0 of differentiation. Data represent two independent experiments. Only significant comparisons between 3T3L1-G972R and 3T3L1-WT cells and between 3T3L1-G972R and 3T3L1-G972R-PIO cells are shown. (A) *Significant increase in 3T3L1-G972R compared with 3T3L1-WT cells $(P<0 \cdot 05) ;{ }^{* *}$ significant decrease in 3T3L1-G972R-PIO compared with 3T3L1-G972R cells $(P<0 \cdot 05)$. (B) \#Significant increase in 3T3L1-G972R compared with 3T3L1-WT cells $(P<0 \cdot 05)$; \#\#significant decrease in 3T3L1-G972R-PIO compared with 3T3L1-G972R cells $(P<0 \cdot 05)$.

adipocyte differentiation (Fig. 6A and B). Thus, compared with 3T3L1-WT cells, 3T3L1-G972R cells showed an increase by $1 \cdot 6$-fold at day $4(P=\mathrm{NS}), 2 \cdot 8$-fold at day $6(P<0 \cdot 01)$, and $2 \cdot 7$-fold at day 8 of differentiation $(P<0.03)$ in the phosphorylation at $\mathrm{Ser}^{473}$. The Akt phosphorylation at $\mathrm{Thr}^{308}$ showed a pattern comparable to $\mathrm{Ser}^{473}$.

No change of Akt content could be observed between the different cell lines during differentiation (data not shown).

Insulin activates Akt through its phosphorylation by PDK1. By immunoblotting with an antibody specific for the $\mathrm{Ser}^{241}$ phosphorylated region of PDK1, we investigated whether the higher activation of Akt in 3T3L1-G972R cells could be associated with higher activation of PDK1. No significant difference in phosphorylation of PDK1 between the cell lines was observed (data not shown).

Despite the reduction in G972R IRS-1-associated PI 3-kinase activity, the G972R variant induces activation of Akt (in both $\mathrm{Thr}^{308}$ and Ser ${ }^{473}$ phosphorylated sites) more strongly than WT IRS-1. Since Akt activation does not necessarily correlate with adipocyte differentiation but is both necessary and sufficient for cell survival and for the regulation of the apoptotic machinery (Datta et al. 1999), we assessed the activation of FKHRL1 during adipocyte differentiation by immunoblotting with antibody specific for the phosphorylated form of FKHRL1, which is a Forkhead family member of transcription factors involved in the apoptosis process and is phosphorylated by Akt. In the absence of phosphorylation, Forkhead family members, which are localized to the nucleus, bind to specific DNA elements that act as potent activators of gene involved in apoptosis. In 3T3L1-WT cell lines, high levels of FKHRL1 phosphorylation are present at day 0 of differentiation, but the levels of phosphorylation decrease during the differentiation process. However, in 3T3L1G972R cells, the levels of FKHRL1 phosphorylation remain high during the process of adipocyte differentiation in homology with Akt. Thus, compared with 3T3L1-WT cells, 3T3L1-G972R cells showed $1 \cdot 4$-fold increase at day 4 of differentiation $(P<0 \cdot 05), 4 \cdot 2$-fold 
WB: p-FKHRL1 $\left(\mathrm{Thr}^{32}\right)$ Ab

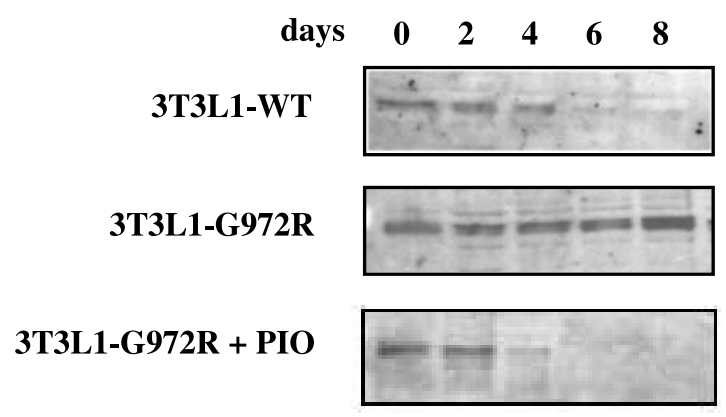

\section{$\square$ 3T3L1-WT}

3T3L1-G972R

3T3L1-G972R-PIO

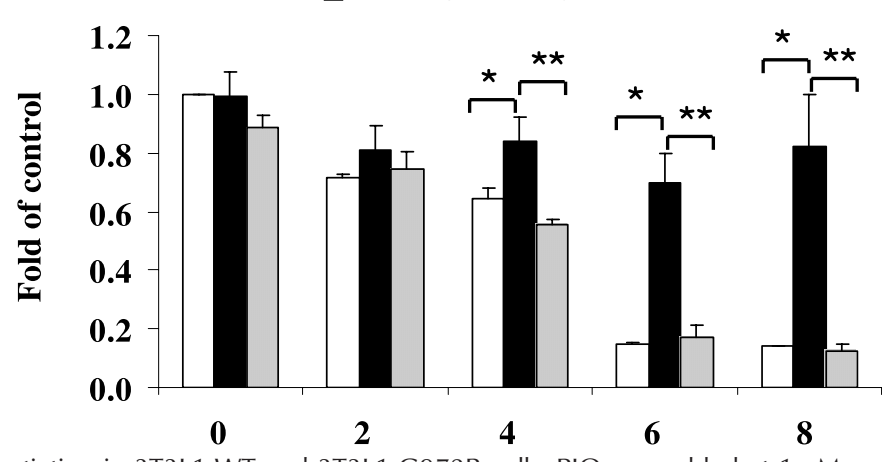

Figure 7 Induced activation of FKHRL1 during adipocyte differentiation in 3T3L1-WT and 3T3L1-G972R cells. PIO was added at $1 \mu \mathrm{M}$ from the induction step of differentiation until full differentiation. Equal amounts of protein lysates at the indicated days of differentiation, as described in Materials and Methods, were separated by SDS-PAGE and immunoblotted with antibody specific for the phosphorylated form of FKHRL1. Protein levels of phosphorylated FKHRL1 were normalized by the value in control cells at day 0 of differentiation. Data represent at least two independent experiments. ${ }^{*}$ Significant increase in 3T3L1-G972R compared with 3T3L1-WT cells $(P<0 \cdot 05)$;

${ }^{* *}$ significant decrease in 3T3L1-G972R-PIO compared with 3T3L1-G972R cells $(P<0 \cdot 05)$.

at day $6(P<0 \cdot 02)$ and $4 \cdot 8$-fold at day $8(P<0 \cdot 014)$ (Fig. 7). These results suggest a possible involvement of Akt in the survival of the 3T3L1-G972R cells by inhibition of FKHRL1.

\section{Activation of $p 42 / p 44$ MAP kinases}

To determine whether the G972R variant in the IRS-1 gene could also activate the pathway involving MAP kinases, we assayed the activation of p42/p44 MAP kinases during differentiation by immunoblotting cell lysates with antiphospho-p42/p44 MAP kinase antibody (Fig. 8A). Interestingly, in 3T3L1-G972R cells, phosphorylated (active) p42/p44 MAP kinases were lower by $1 \cdot 6$-fold at day 0 of differentiation $(P<0 \cdot 012)$, higher by 1.3 -fold at day $2(P<0.03)$ and higher by 1.8 -fold at day 4 $(P<0.027)$ than in 3T3L1-WT cells. To confirm the higher level of phosphorylated p42/p44 MAP kinases in 3T3L1-G972R cells, we performed a time-course experiment after insulin stimulation (100 $\mathrm{nM} \mathrm{0-40} \mathrm{min).}$ Immunoblot analysis showed that in 3T3L1-G972R cells the levels of $\mathrm{p} 42 / \mathrm{p} 44$ MAP kinase phosphorylation remained higher by $3 \cdot 8$-fold $(P<0 \cdot 003), \quad 4 \cdot 7$-fold $(P<0 \cdot 013)$ and $1 \cdot 8$-fold $(P<0 \cdot 03)$ after 5-, 10- and 20 -min stimulation respectively than in 3T3L1-WT cells (Fig. 8B).

PIO enhances adipocyte differentiation and increases PPAR $\gamma$ expression in 3T3L1-G972R cells

Thiazolidinediones are known to promote adipocyte differentiation (Takamura et al. 2001) through PPAR $\gamma$ induction. We tested the hypothesis that PIO could reverse the impaired signaling and restore 3T3L1 adipocyte differentiation. Confluent 3T3L1-G972R preadipocytes were committed to adipocytes by exposing them to PIO in addition to insulin, isobutylmethylxanthine and dexamethasone. After induction, preadipocytes carrying the G972R variant accumulated fat, and a differentiated phenotype with more than $70 \%$ of the cells containing multilocular fat droplets could be observed by day 6 after induction (Fig. 1C). We then assessed the expression of PPAR $\gamma$ during adipocyte differentiation by immunoblotting and RT-PCR. Treatment of the 3T3L1G972R with PIO enhanced PPAR $\gamma$ expression by $1 \cdot 8$-fold at day 2 of differentiation $(P=\mathrm{NS}), 2 \cdot 5$-fold $(P<0 \cdot 012)$ at day $4,2 \cdot 2$-fold $(P<0 \cdot 011)$ at day 6 and $2 \cdot 1$-fold $(P<0 \cdot 044)$ at day 8 compared with untreated 3T3L1-G972R cells (Fig. 2C). We also assessed the expression of adipoQ and adipsin by RT-PCR. As expected, we observed an increase in the expression of all these markers in the 3T3L1-G972R cells treated with PIO compared with the untreated 3T3L1-G972R cells (data not shown).

PIO restores IRS-1 tyrosine phosphorylation, association of $p 85$ with IRS-1, and PI 3-kinase activity in 3T3L1-G972R cells

Treatment of the 3T3L1 cells with $10 \mu \mathrm{M}$ PIO, which has been shown to enhance insulin signaling (Iwata et al. 2001), does not cause a significant increase in amount of IRS-1 protein in the two cell lines but does cause an increase in IRS-1 tyrosine phosphorylation of 1.04-fold $(P=\mathrm{NS})$ in 3T3L1-WT and 1.1-fold $(P=\mathrm{NS})$ in 3T3L1G972R cells (Fig. 3A). Binding of p85 subunit to IRS-1 is increased by $1 \cdot 02$-fold $(P=\mathrm{NS})$ in $3 \mathrm{~T} 3 \mathrm{~L} 1-\mathrm{WT}$ and by $1 \cdot 2$-fold $(P<0 \cdot 03)$ in 3 T3L1-G972R cells. Thus, binding of p85 subunit to IRS-1 in 3T3L1-G972R cells is 


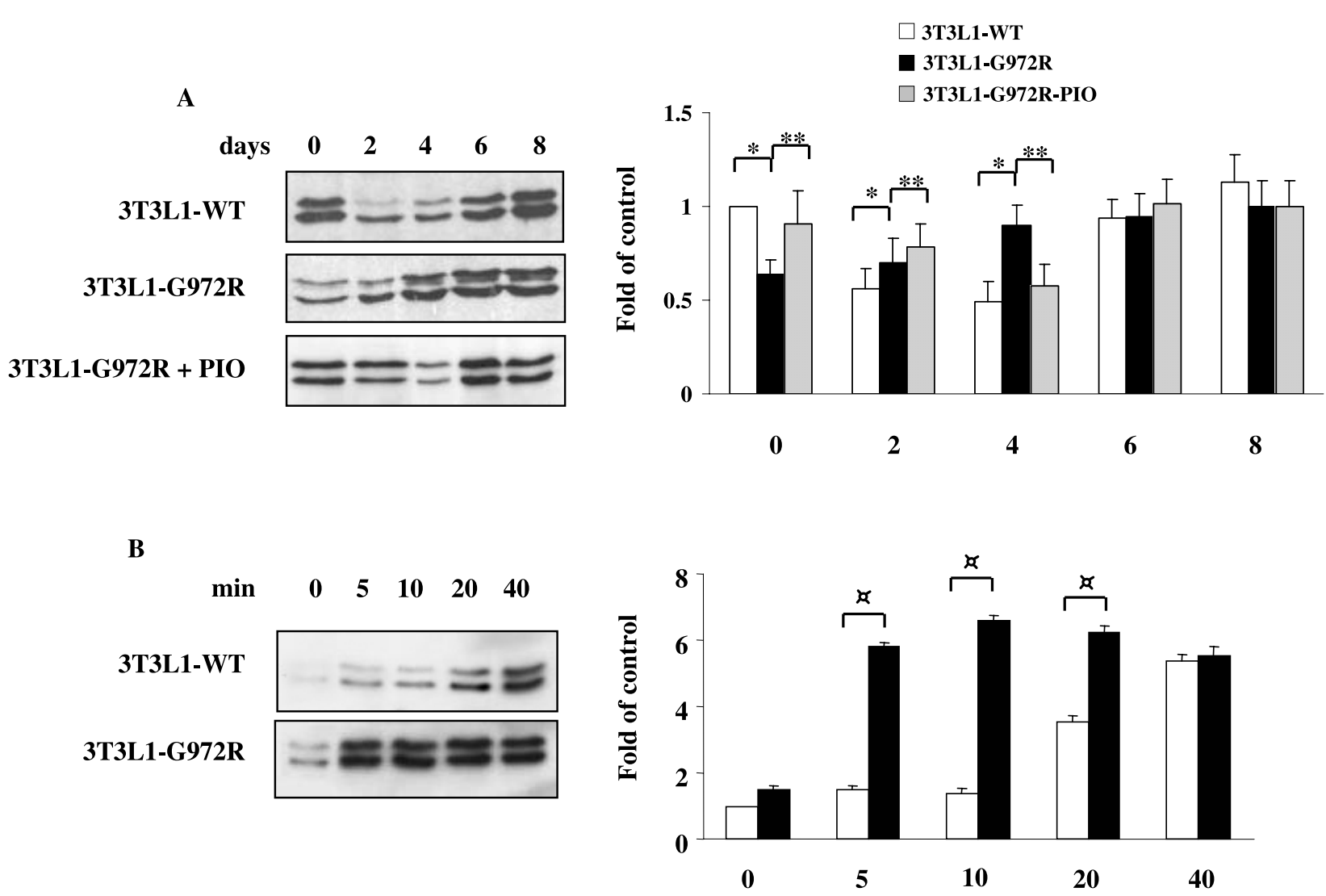

Figure 8 (A) p42/p44 MAP kinase phosphorylation during adipocyte differentiation in 3T3L1-WT, 3T3L1-G972R and 3T3L1-G972R-PIO cells. Protein lysates were immunoblotted with antiphospho-MAPKs antibody. PIO was added at $1 \mu \mathrm{M}$ from the induction step of differentiation until full differentiation. Data represent three independent experiments. Time course (B) of insulin-stimulated (100 nM, 0-40 min) p42/p44 MAP kinase phosphorylation in confluent (day 0 of differentiation) 3T3L1 cells. Data from two separate experiments were calculated as fold of basal. aSignificant increase in 3T3L1-G972R compared with 3T3L1-WT cells $(P<0 \cdot 05)$.

comparable to the insulin-stimulated association of $\mathrm{p} 85$ with IRS-1 in 3T3L1-WT cells (Fig. 3B). Similarly, PI 3 -kinase activity was increased by $1 \cdot 4$-fold $(P<0 \cdot 01)$ in 3T3L1-WT and 1·3-fold $(P<0 \cdot 04)$ in 3T3L1-G972R cells (Fig. 4).

For better analysis of the direct effect of G972R IRS-1 in insulin signaling, we studied the effect of long-term PIO treatment in fully differentiated adipocytes. In particular, we have exposed fully differentiated 3T3L1G972R-PIO cells to $10 \mu \mathrm{M}$ PIO for an extra $48 \mathrm{~h}$ after day 8 of differentiation. The extra $48-\mathrm{h}$ incubation were chosen in order to ensure complete disappearance of metabolically active PIO from medium after withdrawal. Results showed that IRS-1 phosphorylation and binding to PI 3-kinase were reduced respectively by $1 \cdot 1$-fold $(P<0.03)$ and 1.9 -fold $(P<0.002)$ in cells without PIO compared with those where PIO was not withdrawn (Fig. 3C and D). This indicates that the G972R variant directly affects binding of IRS-1 to PI 3-kinase, since this defect is remedied by the presence of PIO.
Effect of PIO on IR tyrosine phosphorylation and interaction with IRS-1

After treatment with PIO, the binding of IRS-1 to the IR is increased by 1.5 -fold $(P<0.01)$ in 3T3L1-WT and 1.01-fold $(P=\mathrm{NS})$ in 3T3L1-G972R cells compared with insulin-stimulated cells (Fig. 5A). Treatment of the 3T3L1 cells with PIO also causes an increase in IR tyrosine phosphorylation of $1 \cdot 1$-fold $(P=\mathrm{NS})$ in 3T3L1-WT and $1 \cdot 4-$ fold $(P<0 \cdot 02)$ in 3T3L1-G972R cells (Fig. 5B).

PIO restores both $\mathrm{Ser}^{473}$ and $\mathrm{Thr}^{308}$ phosphorylation of Akt

Treatment of the 3T3L1-G972R cells with PIO caused a reduction in both $\mathrm{Thr}^{308}$ and $\mathrm{Ser}^{473}$ phosphorylation of Akt during adipocyte differentiation, as in 3T3L1-WT cells (Fig. 6A and B). In comparison with 3T3L1-G972R cells, treatment of 3T3L1-G972R cells with PIO caused a decrease of $3 \cdot 3$-fold at day 6 of differentiation $(P<0 \cdot 01)$ and $3 \cdot 5$-fold at day $8(P<0 \cdot 01)$ in the phosphorylation 


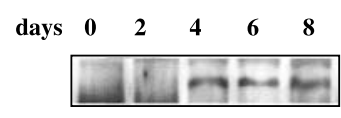

3T3L1-G972R

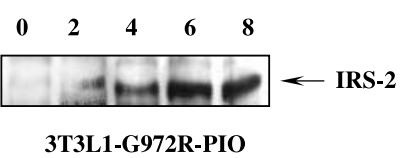

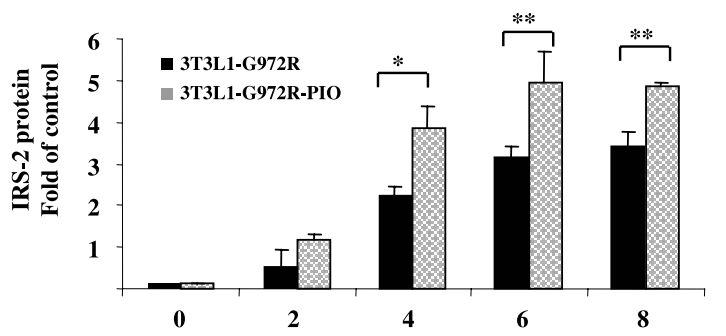

Figure 9 Effect of PIO on IRS-2 expression during adipocyte differentiation. Transfected 3T3L1 were incubated in presence or absence of $1 \mu \mathrm{M} \mathrm{PIO}$ for 8 days. Protein lysates were immunoblotted with monoclonal anti-IRS-2 antibody. Data represent at least two independent experiments. Significant increase in 3T3L1-G972R cells after PIO treatment is shown $\left({ }^{*} P<0 \cdot 05 ;{ }^{* *} P<0 \cdot 01\right)$.

at $\mathrm{Ser}^{473}$. The phosphorylation of Akt at $\mathrm{Thr}^{308}$ showed a pattern comparable to $\mathrm{Ser}^{473}$.

In homology with Akt, FKHRL1 phosphorylation in 3T3L1-G972R cells with PIO caused a decrease of $1 \cdot 6$-fold at day 4 of differentiation $(P<0 \cdot 04), 3 \cdot 7$-fold at day $6(P<0 \cdot 03)$ and $6 \cdot 1$-fold at day $8(P<0 \cdot 02)$ (Fig. 7$)$.

\section{PIO restores $p 42 / p 44$ MAP kinase phosphorylation}

Treatment of the 3T3L1-G972R with PIO restored p42/p44 MAP kinase phosphorylation during adipocyte differentiation to levels similar to 3T3L1-WT cells (Fig. 8A). Compared with 3T3L1-G972R cells, 3T3L1G972R-PIO cells showed an increase of $1 \cdot 4$-fold at day 0 of differentiation $(P<0 \cdot 01)$, a decrease of $1 \cdot 2$-fold at day 2 $(P<0 \cdot 04)$ and a decrease of 1.7 -fold at day $4(P<0 \cdot 008)$ in the amount of phosphorylated (active) p42/p44 MAP kinases, results similar to those of 3T3L1-WT.

\section{PIO increases IRS-2 expression}

It has been recently demonstrated that PPAR $\gamma$ activation rapidly turns on the gene of the key signaling molecule IRS-2 (Smith et al. 2001), which is then phosphorylated in tyrosine and associates with p85, although less than IRS-1, in 3T3L1 cells (Inoue et al. 1998). Therefore, we analyzed the effect of PIO on IRS-2 expression in transfected 3T3L1 cells during adipocyte differentiation.

In untreated 3T3L1-G972R cells, IRS-2 expression is low at days 0 and 2 of differentiation and is modestly increased during the process of adipocyte differentiation (Fig. 9). Conversely, in 3T3L1-G972R cells treated with PIO, we observed a greater increase in the expression of IRS-2 gene. Thus, compared with untreated 3T3L1G972R cells, IRS-2 expression in 3T3L1-G972R-PIO cells was $1 \cdot 7$-fold higher at day 4 of differentiation $(P<0 \cdot 045), 1 \cdot 8$-fold at day $6(P<0 \cdot 004)$ and $1 \cdot 6$-fold at day $8(P<0 \cdot 008)$.

\section{Discussion}

IRS-1 is considered the major IRS in most insulinsensitive tissue. Genetic analysis of the IRS-1 gene has revealed several base-pair changes that result in aminoacid substitution (Almind et al. 1993, Laakso et al. 1994, Hitman et al. 1995, Imay et al. 1997), and the most common of these is a glycine to arginine substitution at codon 972 (G972R), which has been shown to be strongly associated with obesity (Clausen et al. 1995, Baroni et al. 2001). Furthermore, higher insulin resistance is associated with the G972R variant in obese subjects, suggesting an interaction between the G972R mutation and obesity (Clausen et al. 1995, Baroni et al. 2001). These observations led us to carry out a functional study to assess whether there could be a direct impact of this genetic variant on insulin signaling in adipocytes.

We observed that 3T3L1 cells transfected with the G972R variant did not differentiate, thus suggesting that this variant affects insulin signaling during adipocyte differentiation. Indeed, in 3T3L1-G972R cells, the expression of the PPAR $\gamma$ gene was significantly reduced, together with a low level of expression of the specific adipocyte differentiation markers aP2, adiponectin and adipsin.

In the attempt to determine at which step the G972R variant could alter adipocyte differentiation, we examined several proteins involved in insulin signaling downstream of IRS-1. During activation of PI 3-kinase, the SH2 domains of p 85 regulatory subunit bind directly to specific phosphorylated YMXM motifs present in the IRS-1 protein and consequently undergo the conformational changes required for the activation of the catalytic subunit p110 of the PI 3-kinase (Meyers et al. 1996). We found that, after insulin stimulation, the G972R variant in 3T3L1 cells caused a $17 \%$ decrease in IRS-1 phosphorylation. Furthermore, the 3T3L1-G972R cells exhibited $25 \%$ lower binding of p 85 subunit to IRS-1 in response to insulin, in agreement with previous reports in other cell types (Almind et al. 1996, Hribal et al. 2000, Federici et al. 2001, McGettrick et al. 2004). We therefore determined the PI 3-kinase activity directly associated with IRS-1, and cells expressing the G972R variant of IRS-1 showed a 35\% reduction in PI 3-kinase activity when compared with cells transfected with WT IRS-1. Recently, it has been demonstrated that PTEN, a phosphoinositide 3-phosphatase that, by metabolizing PtdIns $(3,4,5) \mathrm{P}_{3}$, acts to suppress the PI 3-kinase/Akt pathway, plays a major role in antagonizing insulin signaling (Lo et al. 2004). The phosphorylation of the PTEN tail of three residues (S380, T382 and T383) regulates 
protein stability and activity. We assessed the activity of PTEN by immunoblotting lysates from 3T3L1-WT and 3T3L1-G972R cells with anti-phospho-PTEN (Ser380) antibody, but found no difference in phosphorylation levels of PTEN between the two cell lines (data not shown).

A recent study showed that the presence of the G972R polymorphism markedly enhanced the association of the IRS-1 gene with the IR, allowing IRS-1 to act as an inhibitor of IR autophosphorylation (McGettrick et al. 2004). In order to determine the mechanism by which the phosphorylation of the G972R IRS-1 protein and its binding to $\mathrm{p} 85$ are reduced, we evaluated the association between IRS-1 and the IR. We observed that the interaction between the IR and the IRS-1 protein is enhanced in 3T3L1-G972R cells compared with 3T3L1WT; in addition, the autophosphorylation of the IR is significantly inhibited.

Since PI 3-kinase is an upstream activator of Akt, we investigated whether the G972R variant alters Akt activation. Furthermore, since the activation of $\mathrm{p} 42 / \mathrm{p} 44$ MAP kinases by insulin is PI 3-kinase/Ras dependent, we also investigated whether the decrease in $\mathrm{p} 85$ binding to G972R IRS-1 might influence p42/p44 MAP kinase signaling (Suga et al. 1997). Surprisingly, the IRS1 G972R variant was found to be associated with a strong activation of Akt (in both $\mathrm{Thr}^{308}$ and $\mathrm{Ser}^{473}$ phosphorylated sites) and of $\mathrm{p} 42 / \mathrm{p} 44$ MAP kinases compared with WT IRS-1. The higher activation of Akt in 3T3L1G972R cells was not associated with higher activation of PDK1. It should be pointed out that Akt activation does not necessarily correlate with adipocyte differentiation, because both insulin and other growth factors, such as platelet-derived growth factor, activate Akt in 3T3L1 preadipocytes, but only insulin induces adipogenesis (Gagnon et al. 1999). Moreover, a few studies have observed that Akt may be activated by a PI 3-kinaseindependent pathway (Kim et al. 1999, Venable et al. 2000, Nadler et al. 2001). Moreover, several studies have demonstrated that under certain circumstances (stress, growth factors, withdrawal, UV irradiation, matrix detachment, DNA damage or survival factors), Akt activity is both necessary and sufficient for cell survival and regulation of the apoptotic machinery (Chen et al. 1998, Biggs et al. 1999, Datta et al. 1999). In support of this hypothesis is the observation that Forkheads, which are potent activators of genes involved in apoptosis and are inactivated by Akt through phosphorylation, are strongly phosphorylated (thus inactive) in 3T3L1-G972R cells. Thus, the high levels of Akt and FKHRL1 phosphorylation that we observed in 3T3L1-G972R cells might be explained as a response to cellular stress due to impairment of insulin signaling.

An antagonistic relationship between p42/p44 MAP kinase activation and adipocytic differentiation has been described (Font de Mora et al. 1997), together with the observation that MAP kinase activation in 3T3L1 cells mediates signaling events that oppose differentiation, such as mitogenesis. It has been shown that upon reaching confluence (day 0), 3T3L1 cells undergo limited clonal expansion (days 1-2), postmitotic growth arrest (days 3-4) and terminal differentiation (days 4-10). The postmitotic growth arrest, referred to as $G_{D}$, has been shown to be required for terminal differentiation (Delmas et al. 2001). Interestingly, in 3T3L1-G972R, we observed at days 2 and 4 (days of commitment of 3T3L1 differentiation) an increase in p42/p44 MAP kinase phosphorylation compared with 3T3L1-WT. This observation suggests that, since insulin signaling is impaired by the G972R variant, the Ras/ERK pathway is activated, stimulating proliferation instead of differentiation.

In summary, we observed that the G972R variant of the IRS-1 gene impairs insulin signaling and adipocyte differentiation in vitro, and it appears to exert its action in a negative-dominant-like manner. Thus, we studied whether the treatment with PPAR $\gamma$ agonists, which have been shown to promote adipocyte differentiation and to improve insulin sensitivity by upregulating PPAR $\gamma$ mRNA levels (Takamura et al. 2001), could modify the negative effects of the G972R variant.

In rats, it has been shown that treatment with PIO increases the number of small adipocytes (which are fully responsive to insulin), together with the reduction of existing large adipocytes (de Souza et al. 2001). Different mechanisms have been proposed on how a receptor expressed predominantly in fat tissue may improve insulin sensitivity in all of the major insulin-sensitive tissues. It has been suggested (Smith 2002) that improvement of insulin sensitivity may be explained by the endocrine function of adipose tissue, where PPAR $\gamma$ agonists, by restoring adipocyte physiology, can improve the release of adipokines that are known to modulate insulin action, such as adiponectin.

Treatment of the 3T3L1-G972R with PIO enhanced PPAR $\gamma$ expression and restored adipocyte differentiation. Phosphorylation of Akt and p42/p44 MAP kinases returned to levels comparable to 3T3L1-WT cells. Adiponectin mRNA was also restored to normal levels. Miyazaki et al. (2003) have shown in vivo that rosiglitazone treatment enhances downstream insulin-receptor signaling in muscle. In particular, IRS-1 tyrosine phosphorylation and p85 binding are significantly improved, an effect similar to what we observed in vitro.

This was particularly evident in fully differentiated 3T3L1-G972R-PIO cells exposed to long-term PIO incubation, where we observed that IRS-1 binding to PI 3-kinase was maintained in cells with PIO compared with those where PIO was withdrawn, thus indicating that the G972R variant directly affects binding of IRS-1 to PI 3-kinase. Moreover, previous studies have shown that treatment of 3T3L1 adipocytes with PIO alone increased both protein levels and insulin-stimulated tyrosine 
phosphorylation of IR and IRS-1 (Iwata et al. 2001). Association of p85 with IRS-1 and PI 3-kinase activity were also increased by PIO (Iwata et al. 2001). Since $\operatorname{PPAR} \gamma$ has been reported to cross-regulate $\mathrm{C} / \mathrm{EBP} \alpha$, and the regulatory regions in IR and IRS-1 genes were reported to contain C/EBP-binding sequence (Wu et al. 1999), the activation of PPAR $\gamma$ by PIO may affect expression of $\mathrm{C} / \mathrm{EBP} \alpha$, which in turn increases expression of IR and IRS-1. In fact, in our study, we observed that treatment with PIO of 3T3L1-G972R cells caused an increase in the amount of IRS-1 protein (although not statistically significantly). We can speculate that this increase helps to improve the IRS-1/PI 3-kinase pathway and activity.

Furthermore, Smith et al. (2001) demonstrated that, in both differentiated 3T3L1 and human adipose tissue, there is a specific activation of the IRS-2 gene by PPAR $\gamma$ agonists, without change in IRS-1, suggesting that this is one of the mechanisms of the insulin-sensitizing effect of these drugs. Previous studies have shown that the different localization of IRS-1 and IRS-2 may explain why IRS-2 contributes less to tyrosine phosphorylation of IRS proteins and p85 association than IRS-1 in 3T3L1 adipocytes. Tyrosine phosphorylation of IRS-1 declines slowly over $10 \mathrm{~min}$ after insulin stimulation, while IRS-2 phosphorylation declines more rapidly (Inoue et al. 1998).

In our study, treatment with PIO of 3T3L1-G972R cells caused an increase in the expression of IRS-2 gene, compared with untreated 3T3L1-G972R, and a concomitant normalization of the insulin-induced signaling pathway, overcoming the block caused by the presence of the G972R variant. Thus, it seems likely that the increase in both IRS-1 and IRS-2 expression helps to ameliorate the insulin signaling in these cells. Finally, the increase in IR autophosphorylation induced by PIO, probably through the increase in IR and IRS-1/IRS-2 expression, may be another mechanism by which PIO may improve insulin action.

Previous studies have shown that the G972R variant of the IRS-1 gene is strongly associated with insulin resistance in obesity (Clausen et al. 1995, Baroni et al. 2001). It seems that this variant in vivo does not affect adipocyte differentiation but may impair insulin action. Control of preadipocyte to adipocyte progression is crucial in regulating energy storage and release. In complex organisms with balanced energy homeostasis, only a portion of the preadipocyte pool become differentiated adipocytes; the rest of the preadipocytes remain quiescent. A complex pattern of factors (including food intake, hormonal stimulation, growth factors, cytokines with opposite effects and fat cell size) interact to maintain an adequate number of small differentiated adipocytes, which are fully responsive to insulin. It should also be noted that adipose tissue contains not just mature adipocytes, but a variety of cell types, including fibroblasts, endothelial cells and preadipocytes at various stages of development, all contributing to the local milieu that regulates adipogenesis. The loss of differentiation in vitro could be explained as inability to reproduce the same conditions as in vivo, where several cofactors act to stimulate adipocyte differentiation. Thus, in vivo, the impairment of insulin signaling determined by the G972R variant may cause insulin resistance without affecting adipocyte differentiation.

In conclusion, we have demonstrated that the G972R variant impairs insulin action in 3T3L1 cells. Impairment of insulin signaling by the G972R variant of IRS-1 has also been demonstrated in other cell types, such as L6 miocytes (Hribal et al. 2000), human pancreatic islets (Federici et al. 2001) and myeloid progenitor 32D(IR) (Almind et al. 1996). Furthermore, we have shown that the G972R variant binds with higher affinity to IR, thus reducing IR autophosphorylation and inhibiting insulin signaling, as described previously by Kahn and coworkers (McGettrick et al. 2004).

Taken together, these observations indicate that this IRS-1 gene variant affects insulin action, and support the hypothesis that this variant is involved in the pathogenesis of insulin resistance. We have also shown that treatment with PPAR $\gamma$ agonists restores normal 3T3L1 adipocyte differentiation and insulin signaling. Subjects carrying this variant have been shown to be more insulin resistant, particularly when obesity is present. If confirmed in vivo, these observations may have application in the treatment of insulin resistance in genetically predisposed obese subjects.

\section{Acknowledgements}

We thank Prof. Giorgio Sesti (Department of Clinical and Experimental Medicine, University of Catanzaro 'Magna Grecia', Italy) for comments and suggestions, and Takeda Chemical Industries, Osaka, Japan, for kindly providing the thiazolidinedione compound PIO.

Financial support for this work was provided by the Faculty of Medicine (grant no. C26F022871) of the University of Rome 'La Sapienza', by the Ministry of Education, University and Science (MURST grant no. 9906021327-014 1999) and by the Ministry of Health (grant no. RF2002), all to M G Baroni. The authors declare that there is no conflict of interest that would prejudice the impartiality of this scientific work.

\section{References}

Alessi DR 2001 Discovery of PDK1, one of the missing links in insulin signal transduction. Biochemistry Society Transactions 29(Pt 2) 1-14.

Almind K, Bjorbaek C, Vestergaard H, Hansen T, Echwald S \& Pedersen O 1993 Amino acid polymorphism of insulin receptor substrate-1 in non-insulin-dependent diabetes mellitus. Lancet $342828-832$. 
Almind K, Inoue G, Pedersen O \& Kahn R 1996 A common amino acid polymorphism in insulin receptor substrate-1 causes impaired insulin signaling. Journal of Clinical Investigation 97 2569-2575.

Auwerx J 1999 PPAR $\gamma$, the ultimate thrifty gene. Diabetologia 42 1033-1049.

Baroni MG, Arca M, Sentinelli F, Buzzetti R, Capici F, Lovari S, Vitale M, Romeo S \& Di Mario U 2001 The G972R variant of the insulin receptor substrate-1 (IRS-1) gene, body fat distribution and insulin-resistance. Diabetologia 44 367-372.

Biggs WH III, Meisenhelder J, Hunter T, Cavenee WK \& Arden KC 1999 Protein kinase B/Akt-mediated phosphorylation promotes nuclear exclusion of the winged helix transcription factor FKHR1. PNAS 96 7421-7426.

Chen RH, Su YH, Chuang RLC \& Chang TY 1998 Suppression of transforming growth factor beta-induced apoptosis through a phosphatidylinositol 3-kinase/Akt-dependent pathway. Oncogene 17 1959-1968.

Clausen JO, Hansen T, Bjorbaek C, Echwald SM, Urhammer SA, Rasmussen S, Andersen CB, Hansen L, Almind K, Winther K et al. 1995 Insulin resistance: interactions between obesity and a common variation of insulin receptor substrate-1. Lancet 346 397-402.

Datta SR, Brunet A \& Greenberg ME 1999 Cellular survival: a play in three Akts. Genes and Development 13 2905-2927.

de Souza CJ, Eckhardt M, Gagen K, Dong M, Chen W, Laurent D \& Burkey BF 2001 Effects of pioglitazone on adipose tissue remodeling within the setting of obesity and insulin resistance. Diabetes 50 1863-1871.

Delmas C, Manenti S, Boudjelal A, Peyssonnaux C, Eychene A \& Darbon JM 2001 The p42/p44 mitogen-activated protein kinase activation triggers $\mathrm{p} 27^{\mathrm{Kip} 1}$ degradation independently of CDK2/cyclin E in NIH 3 T3 cells. Journal of Biological Chemistry 14 34958-34965.

Federici M, Hribal ML, Ranalli M, Marselli L, Porzio O, Lauro D, Borboni P, Lauro R, Marchetti P, Melino G \& Sesti G 2001 The common Arg 972 polymorphism in insulin receptor substrate-1 causes apoptosis of human pancreatic islets. FASEB J 15 22-24.

Font de Mora J, Porras A, Ahn N \& Santos E 1997 Mitogen-activated protein kinase activation is not necessary for, but antagonizes, 3T3-L1 adipocytic differentiation. Molecular and Cellular Biology 17 6068-6075.

Franke TF, Kaplan DR \& Cantley LC PI3K 1997 downstream AKTion blocks apoptosis. Cell $\mathbf{8 8}$ 435-437.

Gagnon AM, Chen CS \& Sorisky A 1999 Activation of protein kinase $\mathrm{B}$ and induction of adipogenesis by insulin in 3T3L1 preadipocytes. Diabetes 48 691-698.

Hitman GA, Hawrami K, McCarthy MI, Viswanathan M, Snehalatha C, Ramachandran A, Tuomilehto J, Tuomilehto-Wolf E, Nissinen A \& Pedersen O 1995 Insulin receptor substrate-1 gene mutations in NIDDM: implications for the study of polygenic disease. Diabetologia 38 481-486.

Hribal ML, Federici M, Porzio O, Lauro D, Borboni P, Accili D, Lauro R \& Sesti G 2000 The Gly $\rightarrow$ Arg $^{972}$ amino acid polymorphism in insulin receptor substrate- 1 affects glucose metabolism in skeletal muscle cells. Journal of Clinical Endocrinology and Metabolism 85 2004-2013.

Imai Y, Philippe N, Sesti G, Accili D \& Taylor SI 1997 Expression of variant forms of insulin receptor substrate-1 identified in patients with noninsulin-dependent diabetes mellitus. Journal of Clinical Endocrinology and Metabolism 82 4201-4207.

Inoue G, Cheatham B, Emkey R \& Kahn CR 1998 Dynamics of insulin signaling in 3T3-L1 adipocytes. Differential compartmentalization and trafficking of insulin receptor substrate (IRS)-1 and IRS-2. Journal of Biological Chemistry 8 11548-11555.

Iwata M, Haruta T, Usui I, Takata Y, Takano A, Uno T, Kawahara J, Ueno E, Sasaoka T, Ishibashi $\mathrm{O}$ et al. 2001 Pioglitazone ameliorates tumor necrosis factor- $\alpha$-induced insulin resistance by a mechanism independent of adipogenic activity of peroxisome proliferator-activated receptor- $\gamma$. Diabetes 50 1083-1092.

Kim JB \& Spiegelman BM 1996 ADD1/SREBP1 promotes adipocyte differentiation and gene expression linked to fatty acid metabolism. Genes and Development 10 1096-1107.

Kim YB, Nikoulina SE, Ciaraldi TP, Henry RR \& Kahn BB 1999 Normal insulin-dependent activation of Akt/protein kinase B, with diminished activation of phosphoinositide 3-kinase, in muscle in type 2 diabetes. Journal of Clinical Investigation 104 733-741.

Laakso M, Malkki M, Kekalainen P, Kuusisto J \& Deeb SS 1994 Insulin receptor substrate-1 variants in non-insulin-dependent diabetes. Journal of Clinical Investigation 94 1141-1146.

Lo YT, Tsao CJ, Liu IM, Liou SS \& Cheng JT 2004 Increase of PTEN gene expression in insulin resistance. Hormone and Metabolic Research 36 662-666.

Maeda N, Shimomura I, Kishida K, Nishizawa H, Matsuda M, Nagaretani H, Furuyama N, Kondo H, Takahashi M, Arita Y et al. 2002 Diet-induced insulin resistance in mice lacking adiponectin/ACRP30. Nature Medicine 8 731-737.

Magun R, Burgering BMT, Coffer PJ, Pardasani D, Lin Y, Chabot J \& Sorisky A 1996 Expression of a constitutively activated form of protein kinase C (c-Akt) in 3T3-L1 preadipose cells causes spontaneous differentiation. Endocrinology 137 3590-3593.

McGettrick AJ, Feener EP \& Kahn CR 2004 Human IRS-1 polymorphism, G972R, causes IRS-1 to associate with the insulin receptor and inhibit receptor autophosphorylation. Journal of Biological Chemistry 280 6441-6446.

Meyers MG \& White MF 1993 The new elements of insulin signaling: insulin receptor substrate-1 and proteins with $\mathrm{SH} 2$ domains. Diabetes 42 643-650.

Meyers MG, Zhang Y, Aldaz GAI, Grammer T, Glasheen EM, Yenush L, Wang LM, Sun XJ, Blenis J, Pierce JH et al. 1996 YMXM motifs and signaling by an insulin receptor substrate 1 molecule without tyrosine phosphorylation sites. Molecular and Cellular Biology 16 4147-4155.

Miyazaki Y, He H, Mandarino LJ \& DeFronzo RA 2003 Rosiglitazone improves downstream insulin receptor signaling in type 2 diabetic patients. Diabetes 52 1943-1950.

Nadler ST, Stoehr JP, Rabaglia ME, Schueler KL, Birnbaum MJ \& Attie AD 2001 Normal Akt/PKB with reduced PI3K activation in insulin-resistant mice. American Journal of Physiology. Endocrinology and Metabolism 281 E1249-E1254.

Nolan JJ, Ludvik B, Beerdsen P, Joyce M \& Olefsky J 1994 Improvement in glucose tolerance and insulin resistance in obese subjects treated with troglitazone. New England Journal of Medicine 3 1188-1193.

Porras A, Alvarez AM, Valladares A \& Benito M 1998 p42/p44 mitogen-activated protein kinases activation is required for the insulin-like growth factor-I/insulin induced proliferation, but inhibits differentiation, in rat fetal brown adipocytes. Molecular Endocrinology 12 825-834.

Sakaue H, Ogawa W, Matsumoto M, Kuroda S, Takata M, Sugimoto T, Spiegelman BM \& Kasuga M 1998 Post-transcriptional control of adipocyte differentiation through activation of phosphoinositide 3-kinase. Journal of Biological Chemistry 273 28945-28952.

Smith U 2002 Impaired ('diabetic') insulin signaling and action occur in fat cells long before glucose intolerance - is insulin resistance initiated in the adipose tissue? International Journal of Obesity and Related Metabolic Disorders 26 897-904.

Smith U, Gogg S, Johansson A, Olausson T, Rotter V \& Svalstedt B 2001 Thiazolidinediones (PPARgamma agonists) but not PPARalpha agonists increase IRS-2 gene expression in 3T3-L1 and human adipocytes. FASEB J 15 215-220.

Spiegelman BM 1998 PPAR $\gamma$ : adipogenic regulator and thiazolidinedione receptor. Diabetes 47 507-514.

Suga J, Yoshimasa Y, Yamada K, Yamamoto Y, Inoue G, Okamoto M, Hayashi T, Shigemoto M, Kosaki A, Kuzuya H et al. 1997 
Differential activation of mitogen-activated protein kinase by insulin and epidermal growth factor in 3T3-L1 adipocytes. Diabetes 46 735-741

Takamura T, Nohara E, Nagai Y \& Kobayashi K 2001 Stage-specific effects of a thiazolidinedione on proliferation, differentiation and PPAR gamma mRNA expression in 3T3-L1 adipocytes. European Journalk of Pharmacology 22 23-29.

Ueki K, Yamamoto-Honda R, Kaburagi Y, Yamauchi T, Tobe K, Burgering BMT, Coffer PJ, Komuro I, Akanuma Y, Yazaki Y et al. 1998 Potential role of protein kinase B in insulin-induced glucose transport, glycogen synthesis, and protein synthesis. Journal of Biological Chemistry 273 5315-5322.

Venable CL, Frevert EU, Kim YB, Fischer BM, Kamatkar S, Neel BG \& Kahn BB 2000 Overexpression of protein-tyrosine phosphatase-1B in adipocytes inhibits insulin-stimulated phosphoinositide 3-kinase activity without altering glucose transport or Akt/protein kinase B activation. Journal of Biological Chemistry 16 18318-18326.
Wu Z, Rosen ED, Brun R, Hauser S, Adelmant G, Troy AE, McKeon C, Darlington GJ \& Spiegelman BM 1999 Cross-regulation of $\mathrm{C} / \mathrm{EBP} \alpha$ and PPAR $\gamma$ controls the transcriptional pathway of adipogenesis and insulin sensitivity. Molecular Cell 3 151-158.

Zierath JR, Ryder JW, Doebber T, Woods J, Wu M, Ventre J, Li Z, McCrary C, Berger J, Zhang B et al. 1998 Role of skeletal muscle in thiazolidinedione insulin sensitizer (PPAR gamma agonist) action. Endocrinology 139 5034-5041.

Received in final form 7 October 2005

Accepted 17 October 2005

Made available online as an Accepted Preprint 18 November 2005 